FRÜHMITTELALTERLICHE STUDIEN

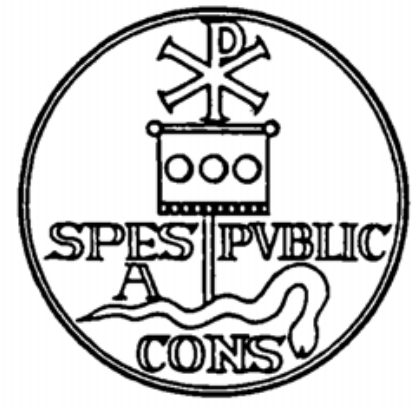





\title{
FRÜHMITTELALTERLICHE STUDIEN
}

\author{
Jahrbuch des Instituts für Frühmittelalterforschung \\ der Universität Münster
}

\author{
in Zusammenarbeit mit \\ Hans Belting, Hugo Borger, Dietrich Hofmann, Albrecht Jockenhövel, \\ Friedrich Ohly, Karl Schmid und Ruth Schmidt-Wiegand \\ unter Mitwirkung von \\ Karl Hauck \\ herausgegeben von \\ HAGEN KELLER und JOACHIM WOLLASCH
}

27. Band

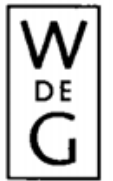

1993 


\section{Redaktion: \\ Dr. Mechthild Sandmann \\ Institut für Frühmittelalterforschung \\ der Universität Münster \\ Salzstraße 41 \\ D-48143 Münster}

ISSN 0071-9706

ISBN 3110141523

(C) Copyright 1993 by Walter de Gruyter \& Co., D-10785 Berlin

Dieses Werk einschließlich aller seiner Teile ist urheberrechtlich geschützt. Jede Verwertung außerhalb der engen Grenzen des Urheberrechtsgesetzes ist ohne Zustimmung des Verlages unzulässig und strafbar. Das gilt insbesondere für Vervielfältigungen, Übersetzungen, Mikroverfilmungen und die Einspeicherung und Verarbeitung in elektronischen Systemen.

Printed in Germany

Satz und Druck: Arthur Collignon GmbH, Berlin

Buchbinderische Verarbeitung: Lüderitz \& Bauer $\mathrm{GmbH}$, Berlin 